\title{
Liquid Anion Exchange Chromatographic Extraction and Separation of Osmium(VIII) with 4-(4-Methoxy- benzylideneimino)-5-methyl-4H-1,2,4-triazole-3-thiol in Hydrochloric Acid Medium
}

\author{
KALURAM N. VIDHATE \\ Department of Chemistry, Milind College of Science, Aurangabad-431002, India \\ knvidhate2@gmail.com
}

Received 22 October 2015 / Accepted 20 November 2015

\begin{abstract}
A novel method is proposed for the extraction of microgram level concentration of osmium(VIII) from hydrochloric acid medium with 4-(4-methoxybenzylideneimino)-5-methyl- $4 \mathrm{H}$ 1,2,4-triazole-3-thiol (MBIMTT) dissolved in chloroform as an extractant. The osmium(VIII) from the organic phase is stripped with mixture of thiourea and $2 \mathrm{M}$ hydrochloric acid and determined spectrophotometric method. The method affords the binary separation and determination of osmium(VIII) from synthetic mixture. The method is successfully applied for the separation and determination of osmium from the alloys. The method is highly selective, simple and reproducible.
\end{abstract}

Keywords: Osmium(VIII), Solvent extraction, Alloys

\section{Introduction}

The abundance of osmium in the earth's crust is $0.001 \mathrm{ppm}$. It has wide range of applications as catalyst, hardening agent in alloys, polymer staining, buckminster fullerene adducts. Osmium ccurs with platinum group metals and base metals, it has electronic, industrial and environmental importance. Hence it is of paramount importance in the development of separation method to recover osmium to meet the future demand. Solvent extraction has become an effective technique in the recovery and separation of osmium ${ }^{1-4}$. The aqueous chemistry of osmium is extremely complex. The important tendency of osmium is to form chlorocomplex in chloride medium. Solvent extraction technique of separation uses the difference in kinetic behavior for the formation of extractable species as well as the strength of electrostatic interactions of their chlorocomplexes with liquid anion exchanger. The inertness of the chlorocomplex of osmium in aqueous medium plays an important role in the extraction from acidic solution by an anion exchange mechanism. Other extractants reported for osmium(VIII) are trioctyl phosphine oxide ${ }^{5}$, trioctylamine, bis- 2-ethylhexyl phosphoric acid ${ }^{7}$, cynex $925^{8}, N$-n-octylaniline ${ }^{9-12}$. The methods reported 
are not so reliable for routine application because these methods suffer from the drawbacks such as operating condition (emulsion formation leading to problem for the separation, slow equilibrium) and ionic exchanger, nature of diluents, critical $\mathrm{pH}$ range etc.

In the present investigations, extraction behavior of osmium(VIII) using 4-(4methoxybenzylideneimino)-5-methyl-4H-1,2,4-triazole-3-thiol(MBIMTT) dissolved in chloroform as an extractant presence of hydrochloric acid media. MBIMTT has been employed successfully in this laboratory for the extraction of $\mathrm{Rh}(\mathrm{III}), \mathrm{Ru}(\mathrm{III})$ and $\mathrm{Au}(\mathrm{III})$, $\mathrm{Pd}(\mathrm{II})$ and $\mathrm{Pt}(\mathrm{IV}), \operatorname{Ir}(\mathrm{III})^{13-18}$.

\section{Experimental}

A Shimadzu UV-Visible spectrophotometer (UV-1701) with $1 \mathrm{~cm}$ quartz cells was used for measurement. pH measurements were carried out with an Elico digital pH meter model LI$120( \pm 0.01)$

A stock solution of osmium(VIII) was prepared by dissolving $1 \mathrm{~g}$ of osmium tetraoxide (S. D. Fine, India) in dilute AnalaR hydrochloric acid $\left(1 \mathrm{~mol} / \mathrm{dm}^{3}\right)$ and diluting to $100 \mathrm{~mL}$ with distilled water and further standardizing it ${ }^{19}$. A working solution $100 \mu \mathrm{g} \mathrm{mL}^{-1}$ was prepared from it by diluting the stock solution with distilled water. The reagent MBIMTT synthesized by known literature method ${ }^{13}$. MBIMTT $\left(0.1 \mathrm{~mol} / \mathrm{dm}^{3}\right)$ solution was prepared in chloroform.

Other standard solutions of different metal ions used to study the effect of foreign ions were prepared by dissolving weighed quantities of respective salts in distilled water or dilute hydrochloric acid. Solutions of anions were prepared by dissolving the respective alkali metal salts in distilled water. All the chemicals used were of AR grade. Double distilled deionized water was invariably used throughout the measurements.

\section{Recommended method}

An aqueous solution containing $100 \mu \mathrm{g}$ of osmium(VIII) and enough hydrochloric acid and water were added to give final concentration of $1 \mathrm{~mol} / \mathrm{dm}^{3}$ with respect to hydrochloric acid in a total volume of $25 \mathrm{~mL}$. The resulting solution was transferred to $125 \mathrm{~mL}$ separating funnel. The aqueous phase was equilibrated once with $10 \mathrm{~mL}$ of $0.1 \mathrm{~mol} / \mathrm{dm}^{3}$ MBIMTT solution in chloroform for 30 second. The phase was allowed to separate and the metal from the organic phase was backstripped with mixture of $1 \mathrm{~mL} 10 \%$ thiourea and $9 \mathrm{~mL} 2 \mathrm{M}$ hydrochloric acid solution. The extract was evaporated to moist dryness and leached with dilute hydrochloric acid to form the solution. Osmium(VIII) was estimated spectrophotometric method ${ }^{20}$.

\section{Results and Discussion}

\section{Extraction of osmium(VIII) as a function of acid concentration}

The extraction of $100 \mu \mathrm{g}$ osmium(VIII) was carried out from different acid medium with $0.1 \mathrm{~mol} / \mathrm{dm}^{3}$ MBIMTT in chloroform keeping the aqueous to organic volume ratio 2.5:1. The extraction was found to be complete from hydrochloric acid. Osmium(VIII) was extracted over the $0.2-10 \mathrm{~mol} / \mathrm{dm}^{3}$ acidity range with hydrochloric acid with $0.1 \mathrm{~mol} / \mathrm{dm}^{3}$ MBIMTT in chloroform. It was observed that extraction increased in the acidity of the aqueous solution and became quantitative at $1 \mathrm{~mol} / \mathrm{dm}^{3}$ hydrochloric acid. It was incomplete in sulphuric acid due to emulsion formation. The extraction was quantitative in nitric acid medium in the $6-7 \mathrm{~mol} / \mathrm{dm}^{3}$ range, but third-phase formation took place above this range of acidity. Hence, the hydrochloric acid system was used for further studies. 


\section{Effect of reagent concentration}

Osmium(VIII) was extracted over the $0.5-3 \mathrm{~mol} / \mathrm{dm}^{3}$ acidity range with hydrochloric acid with varying concentrations of MBIMTT. The reagent concentration was varied from $1 \times 10^{-5}-2 \mathrm{~mol} / \mathrm{dm}^{3}$. It was observed that extraction increased in the acidity of the aqueous solution and became quantitative at $1 \mathrm{~mol} / \mathrm{dm}^{3}$ hydrochloric acid. It was found that $0.1 \mathrm{~mol} / \mathrm{dm}^{3}$ reagent in chloroform was needed for quantitative extraction of osmium(VIII) from $1 \mathrm{~mol} / \mathrm{dm}^{3}$ hydrochloric acid.

\section{Effect of equilibration time}

Variation of the shaking period from 5 seconds to 5 minutes showed that a minimum 10 second equilibration time is adequate for quantitative extraction of osmium(VIII) from hydrochloric acid media. As a general procedure, 30 second of equilibration time is recommended in order to ensure complete extraction of osmium(VIII) hydrochloric acid medium. Prolonged shaking up to 5 minutes has no adverse effect on the efficiency of extraction.

\section{Effect of diluents}

The extractions were performed from $1 \mathrm{~mol} / \mathrm{dm}^{3}$ hydrochloric acid medium using $0.1 \mathrm{~mol} / \mathrm{dm}^{3}$ MBIMTT in various solvents as diluents. It was found that $0.1 \mathrm{~mol} / \mathrm{dm}^{3}$ MBIMTT solution in carbon tetrachloride, chloroform, xylene, toluene and benzene provides quantitative extraction of osmium(VIII). The extraction of osmium(VIII) was found to be incomplete in isobutyl methyl ketone (66\%), isoamylalcohol (45\%), while no extraction in $n$-butanol and 4-methyl-2-pentanol. Chloroform is recommended for further extraction procedure because it offers better phase separation.

\section{Nature of extracted species}

The composition of complex was confirmed by using $\log \mathrm{D}-\log \mathrm{C}$ plot. The graph $\log$ $\mathrm{D}_{\text {[Os(VIII)] }}$ versus $\log \mathrm{C}_{\text {[MBIMTT] }}$ at $4 \mathrm{~mol} / \mathrm{dm}^{3}$ hydrochloric acid was found to be linear and having slope of 1.3 to be $1: 1$, [Os(VIII): MBIMTT].

\section{Loading capacity of MBIMTT}

The loading capacity of the extractant was determined by the repeated contact of organic phase with a fresh feed solution of the metal of some concentration. For a $10 \mathrm{~mL}$ of 0.1 solution of MBIMTT in chloroform at 1 hydrochloric acid medium and a Aq/Org phase ratio of 2.5:1, the maximum loading capacity for osmium(VIII) was found to be $4.3 \mathrm{mg}$.

\section{Effect of diverse ions}

Various ions were used in order to assess the tolerance of these ions on the extraction of osmium(VIII). Osmium(VIII)was extracted in the presence of different diverse ions (Table 1). The tolerance limit was set as the amount of foreign ions cause $\pm 2 \%$ errors in recovery of osmium. The results showed that in the extraction and determination $100 \mu \mathrm{g}$ of the osmium, these ions did not interfere at the level tested. The reproducibility of osmium extraction investigated from six replicate measurement was found to be $99.00 \pm 0.95 \%$.

\section{Binary separation of osmium(VIII) from base metals}

The method allowed separation and determination of osmium(VIII) from a binary mixture containing either iron(III), cobalt(II), nickel(II) and copper(II). 
Table 1. Effect of diverse ions on the extractive determination of osmium(VIII) Os(VIII) = $100 \mu \mathrm{g} ;$ aqueous phase $=1 \mathrm{~mol} / \mathrm{dm}^{3} \mathrm{HCl} ; \mathrm{Aq} / \mathrm{Org}=25: 10 ;$ extractant $=0.1 \mathrm{~mol} / \mathrm{dm}^{3}$ MBIMTT in chloroform

\begin{tabular}{cl}
\hline Tolerance limit, $\mathrm{mg}$ & \multicolumn{1}{c}{ Foreign ion added } \\
\hline 100 & $\begin{array}{l}\text { Fluride, Citrate, Oxalate, Acetate, EDTA, } \\
\text { Malonate, Bromide, Iodide }\end{array}$ \\
20 & $\mathrm{Ca}(\mathrm{II}), \mathrm{Ba}(\mathrm{II}), \mathrm{Be}(\mathrm{II}), \mathrm{Mg}(\mathrm{II}), \mathrm{Fe}(\mathrm{III})$ \\
15 & $\mathrm{Mn}(\mathrm{II}), \mathrm{Fe}(\mathrm{II}), \mathrm{Cr}(\mathrm{III}), \mathrm{Co}(\mathrm{II})$ \\
10 & $\mathrm{Mo}(\mathrm{VI}), \mathrm{Sr}(\mathrm{II}), \mathrm{Ti}(\mathrm{IV}), \mathrm{Ce}(\mathrm{IV})$ \\
5 & $\mathrm{U}(\mathrm{VI}), \mathrm{Mn}(\mathrm{VII}), \mathrm{Sb}(\mathrm{III}), \mathrm{Zn}(\mathrm{II}), \mathrm{Pb}(\mathrm{II})$, \\
& $\mathrm{Hg}(\mathrm{II}), \mathrm{Ni}(\mathrm{II}), \mathrm{Sn}(\mathrm{II}), \mathrm{Cu}(\mathrm{II})$ \\
\hline
\end{tabular}

The separation of osmium(VIII) from iron(III), cobalt(II), nickel(II) and copper(II) by its extraction with $0.1 \mathrm{~mol} / \mathrm{dm}^{3}$ MBIMTT in chloroform at $1 \mathrm{~mol} / \mathrm{dm}^{3}$ hydrochloric acid. Under these condition all the base metals remain quantitatively in the aqueous phase and these base metals determined spectrophotometrically with thiocyanate ${ }^{21}$, 1-nitroso-2 naphthol ${ }^{21}, \mathrm{DMG}^{21}$ and pyrimidine-2-thiol ${ }^{22}$ respectively. Osmium is stripped from the organic phase with mixyure of $1 \mathrm{ml} 10 \%$ thiourea and $9 \mathrm{~mL}$ of $2 \mathrm{M} \mathrm{HCl}$. The extract was evaporated to moist dryness and leached with $1 \mathrm{~mol} / \mathrm{dm}^{3}$ hydrochloric acid to form the solution. Osmium(VIII) was estimated by spectrophotometric method ${ }^{20}$. The recovery of osmium(VIII) and that added ions was $99.5 \%$ and results are reported in Table 2.

Table 2. Binary separation of osmium(VIII) from iron(III), cobalt(II), nickel(II) and copper(II)

\begin{tabular}{cccc}
\hline Composition of & Recovery* & Relative Standard \\
\cline { 1 - 1 } Metal ions, / $\mu \mathrm{g}$ & & Os(VIII) $\%$ & Deviation $\%$. \\
\hline Os(VIII), 100; Fe(III); 15000 & & 99.6 & 0.13 \\
Os(VIII), 100; Co(II) 10000 & & 99.7 & 0.07 \\
Os(VIII), 100; Ni(II) 5000 & & 99.6 & 0.11 \\
Os(VIII), 100; Cu(II) 5000 & 99.8 & 0.13 \\
\hline
\end{tabular}

*average $f$ six determinations

\section{Separation of osmium(VIII) from multicomponent synthetic mixture}

In its natural occurrence osmium is always associated with the noble and base metals; hence its separation from these metals is of great importance. Under the optimum condition for extraction of osmium(VIII), there is quantitative extraction of $\mathrm{Pd}(\mathrm{II}), \mathrm{Pt}(\mathrm{IV})$ and $\mathrm{Rh}(\mathrm{III})$. But the coextracted metal ions cannot be backstripped by mixture of thiourea and $2 \mathrm{M}$ hydochloric acid solution. Thus the MBIMTT reagent is made selective towards osmium(VIII) by taking advantage of the strippent used. The proposed method allows the selective separation and determination of osmium from many metal ions (Table 3).

\section{Analysis of alloys}

To ascertain the selectivity of the reagent the proposed method was successfully used in the determination of osmium(VIII) in alloys. The real samples were not available; hence the synthetic mixtures were prepared corresponding to the composition of alloy. The results of the analysis are reported in Table 4 . The average recovery of osmium(VIII) has been found to be $99.4 \%$. 
Table 3. Analysis of Synthetic Mixtures

\begin{tabular}{lccc}
\hline \multicolumn{1}{c}{$\begin{array}{c}\text { Composition } \\
\mu \mathrm{g}\end{array}$} & $\begin{array}{c}\text { Osmium } \\
\text { found }^{\mathrm{a}} \mu \mathrm{g}\end{array}$ & $\begin{array}{c}\text { Recovery, } \\
\%^{*}\end{array}$ & $\begin{array}{c}\text { R.S.D. } \\
\%\end{array}$ \\
\hline Os, 100; Pt,500 & 99.7 & 99.4 & 0.05 \\
Os, 100; Pd,500 & 99.4 & 99.8 & 0.07 \\
Os, 100; Ru,500 & 99.7 & 99.8 & 0.07 \\
Os, 100; Rh,500 & 99.6 & 99.6 & 0.05 \\
Os, 100; Pt,500; Ru,500 & 99.7 & 99.7 & 0.06 \\
Os, 100; Pt,500; Pd,500 & 99.6 & 99.6 & 0.07 \\
Os, 100; Pt,500; Rh,500 & 99.5 & 99.5 & 0.07 \\
Os, 100; Pt,500; Ru,500; Pd, 500 & 99.8 & 99.8 & 0.05 \\
Os, 100; Pt,500; Rh,500; Pd, 500 & 99.5 & 99.5 & 0.06 \\
Os, 100; Pt,200; Ru, 200; Pd, 200; Fe, 2000; & & & \\
Co, 2000; Ni, 2000; Cu, 2000 & 99.2 & 99.2 & 0.07 \\
\hline
\end{tabular}

*Average six determination

Table 4. Analysis of Alloys

\begin{tabular}{cccccc}
\hline Alloys & $\begin{array}{c}\text { Composition } \\
\text { of Alloys } \\
\%\end{array}$ & $\begin{array}{c}\text { Osmium(VIII) } \\
\text { taken, } \mu \mathrm{g}\end{array}$ & $\begin{array}{c}\text { Osmium(VIII) } \\
\text { found by proposed } \\
\text { method* } \mu \mathrm{g}\end{array}$ & $\begin{array}{c}\text { Recovery, } \\
\%^{*}\end{array}$ & R.S.D. \\
\hline Siserskite & Os, 80; Ir, 20 & 100 & 99.7 & 99.5 & 0.05 \\
Irodosmine & Os, 25; Ir, 75 & 100 & 99.5 & 99.6 & 0.05 \\
Aurosmiridium & Os, 25; Au, & 100 & 99.7 & 99.5 & 0.06 \\
\hline 25; Ir, 50 & & &
\end{tabular}

${ }^{*}$ Average of six determination

\section{Conclusion}

These results underline the potential of the proposed method for the quantitative, selective extraction of osmium(VIII) with MBIMTT containing low concentration of osmium. It is free from interference from the large number of diverse ions which are associated with osmium(VIII) in its natural occurrence. The important features of this method are low reagent concentration is required, and the time required for the equilibrium is very short (30 seconds). The method is effective to determine and separate the osmium content from the alloys. The method is applicable to the analysis of osmium(VIII) in synthetic mixtures. The method is very simple, selective and reproducible.

\section{References}

1 Dayer F B and Gibson N A, Analyst, 1951, 76, 104-106; DOI:10.1039/AN9517600104

2 Weirsma J H and Lott P F, Anal Chem., 1967, 39(6), 674-676; DOI:10.1021/ac60250a024

3 Das P K and Das H K, J Indian Chem Soc., 1995, 72(2), 145.

$4 \quad$ Enasafi A A and Sollary E S, J Indian Chem Soc., 1995, 34(12)(A), 1005-1008.

5 Rokade M D, Iyer J N and Dhadke P M, Chem Environ Res., 2001, 10, 101-1007.

6 Przeszlakowskis S and Flieger A, Talanta, 1979, 26(12), 1125-1133; DOI:10.1016/0039-9140(79)80028-4

7 Sherikar A V, Phalke P N and Dhadke P M, Indian Chem Technol., 1997, 4, 59-60.

8 Mhaske A and Dhadke P M, Sep Sci Technol., 2002, 37, 1861-1875. 
9 Pohlandt C, Talanta, 1979, 26(3), 199-206; DOI:10.1016/0039-9140(79)80049-1

10 Gedye R N, Bozic J, Durbano P M and Williamson B, Talanta, 1989, 36(10), 1055 1058; DOI:10.1016/0039-9140(89)80194-8

11 Lokhande T N, Anuse M A and Chavan M B, J Soudi Chem Soc., 2000, 4, 1-10.

12 Kokate J K, Aher H R, Han S and Kuchekar S R, Indian J Chem Technol., 2012, 19(4), 239-243.

13 Vidhate K N, Lande M K and Arbad B R, J Indian Chem Soc., 2008, 85, 536-538.

14 Vidhate K N, Gadekar L S, Lande M K and Arbad B R, J Indian Chem Soc., 2008, 86(1), 109-112.

15 Vidhate K N, Uzma P, Lande M K and Arbad B R, J Saudi Chem Soc., 2015, 19(1), 54-58; DOI:10.1016/j.jscs.2011.12.018

16 Vidhate K N, Lande M K and Arbad B R, Adv Appl Sci Res., 2012, 3(2), 713-919.

17 Vidhate K N, Waghmare R A, Katkar S S and Lande M K, Adv Appl Sci Res., 2014, 5(6), 241.

18 Vidhate K N, Adv Appl Sci Res., 2015, 6(7), 180-185.

19 Furman, Standard method chemical Analysis, $6^{\text {th }}$ Edn. Vol.I, Edited by Howell N, Furman and Robert E (Publication company Malabar, Florida), 1962, 905.

20 Sandell E B, Colorimetric Determination of Traces of Metals, $3^{\text {rd }}$ Edn., Edited by Clark B L, Elving P J and Koltoff I M, (Interscience Publishers, INC, New York) 1965, 443, 524, 563.

21 Vogel AI, A Text book of Quantitative Inorganic Analysis, $4^{\text {th }}$ Edn., ELBS, London, 1978, p. 474, 739, 741,747.

22 Kuchekar S R, Anuse M A and Chavan M B, Indian J Chem., 1986, 25A, 1041. 